\title{
INTERVENÇÃO SISTÊMICA NO CONTEXTO DA TERAPIA COM UM HOMEM AUTOR DE VIOLÊNCIA CONTRA MULHER: ESTUDO DE CASO
}

\author{
SYSTEMIC INTERVENTION IN THE CONTEXT OF THERAPY WITH A MAN \\ AUTHOR OF VIOLENCE AGAINST WOMEN: CASE STUDY
}

\begin{abstract}
RESUMO: Este artigo relata o estudo de caso de um homem autor de violência em processo terapêutico em uma Clínica-Escola de Florianópolis. Seu objetivo é compreender a importância da terapia sistêmica para homens autores de violência. Notou-se, nesse sentido, repetição de comportamento familiar, sendo possível uma compreensão intergeracional. Percebeu-se também que as perspectivas utilizadas permitiram adentrar com mais profundidade o mundo vivido do paciente $\mathrm{e}$ seus processos de significação na construção da narrativa de sua trajetória. Espera-se, com este artigo, ampliar possibilidades para 0 atendimento com homens autores de violência.
\end{abstract}

PALAVRAS-CHAVE: Violência familiar; Autor de violência; Teoria Sistêmica.
ABSTRACT: This article reports the case study of a man who committed violence in a therapeutic process at a Clinic School in Florianópolis. It's objective is to understand the importance of systemic therapy for men who commit violence. A repetition of familiar behavior was noticed, being possible an intergenerational understanding. It was noticed that the perspectives used, allowed to penetrate with more depth to the world the patient lived and its processes of signification in the construction of the narrative of its trajectory. This article hopes to expand possibilities for the care with men authors of violence.

KEYWORDS: Domestic Violence; Author of Violence; Systemic Theory.
NÁDIA DE MELO FERREIRA

Universidade Federal de Santa Catarina, Florianópolis/SC, Brasil

\section{INTRODUÇÃo}

Este artigo se desenvolve a partir de um estudo de caso analisado na perspectiva sistêmica que prioriza, sobretudo, o contexto relacional no qual o indivíduo está inserido (Vidal, 2006). Especificamente o caso analisado é de um homem autor de violência contra sua ex-companheira. Ao longo do estudo foram abordadas questões como: (a) quais os impactos que a Lei Maria da Penha gerou na vida de um homem autor de violência contra mulher? (b) Quais as consequências do ato violento na vida deste homem? (c) Quais as transformações produzidas no processo terapêutico?

Os estudos voltados aos homens autores de violência vêm tomando notoriedade na produção científica brasileira, embora, como salientam Lima e Büchelle (2011), estudos e políticas públicas voltadas aos homens autores de violência ainda sejam escassas no Brasil. Entende-se que a violência é relacional e, para apreendê-la, devemos olhar os dois espectros da violência, ou seja, tanto os ditos "agressores", como as ditas "vítimas", pois só assim se pode transcender ao ato violento.
* Artigo derivado de trabalho de conclusão de curso (TCC), produzido no âmbito da formação em Terapia relacional Sistêmica, no Familiare Instituto Sistêmico, Florianópolis, SC.

Recebido em 16/03/2018 Aprovado em 28/01/2019 
Beiras e Nascimento (2017) afirmam que os programas que atendem homens autores de violência se dedicam a promover reflexões e transformações nas relações de gênero, por meio de estratégias diversas para que não ocorra reincidência do ato violento. Evidencia-se a importância de promover grupos reflexivos com homens autores de violência, para que assim possamos caminhar para um maior entendimento sobre o tema, como também contribuir para diminuir a violência e promover a equidade de gênero.

Quando falamos em violência contra a mulher, também estamos falando sobre gênero. A violência, no entanto, não está apenas atrelada ao gênero, mas sim a todas as esferas sociais. Suas características variam de acordo com o tempo e espaço. Minayo (2007) elucida que este é um fenômeno complexo e multicausal. De tal modo, por atingir todas as pessoas e não apenas uma parcela específica da sociedade, ela foge a qualquer conceituação precisa e cabal, já que a violência sofrida e vivenciada será elaborada por cada indivíduo.

Ao falar em gênero, deve-se localizar de onde falamos. Nossa sociedade ocidental é ainda predominantemente machista, patriarcal e sexista. Neste sentido, muitas das relações que presenciamos de violência estão relacionadas a esses padrões sociais que reforçam o caráter submisso e frágil da mulher. Por entender que a violência é complexa, multifatorial e relacional, buscou-se refletir, a partir de um estudo de caso, a importância da terapia sistêmica para homens autores de violência, uma vez que a análise sob a perspectiva sistêmica pondera que, para maior efetividade das intervenções, deve-se considerar não somente indivíduos, mas os sistemas humanos como um todo (Schmidt, Schneider, \& Crepaldi, 2011).
Cabe salientar que se optou por utilizar o termo 'autor de violência', por compartilhar a ideia de alguns autores, como Acosta, Andrade, e Bronz (2004); Toneli, Lago, Beiras, e Climaco (2010), que explicam que o termo 'agressor' acaba por reforçar aspectos identitários que associam a violência como parte natural de ser homem. Neste sentido, acaba-se criando rótulos e generalizações, fixando assim papéis de vítima $\mathrm{x}$ agressor, o que faz com que aquele considerado "agressor” seja excluído do processo.

Corroborando o pensamento de Beiras e Cantera (2012), acredita-se que se faz necessário desconstruir rótulos existentes como "agressor" e pensar em termos como "autor de violência", "perpetrador de violência", "homens que exercitam ou exercem violência"; assim como homens, mulheres ou casais em situações de violência. Neste contexto, ao optar por utilizar o termo 'autor de violência', saímos de possíveis generalizações e papéis fixos e promovemos um olhar mais sistêmico, possibilitando mudanças e alternativas para resolução de conflitos.

Espera-se, por conseguinte, que o presente estudo possa contribuir no sentido de auxiliar tanto profissionais do campo da Psicologia, como de outras áreas do conhecimento no que tange ao atendimento com homens autores de violência contra mulheres. $\mathrm{O}$ artigo também pretende suscitar reflexões no que se refere à prática profissional com homens autores de violência contra mulher.

\section{VIOLÊNCIA E SUAS REPERCUSSÕES}

A violência pode ser compreendida e analisada através de alguns vieses, seja por meio da psicologia, sociologia, antropologia, filosofia, direito e 
outras áreas do conhecimento. A Organização Mundial da Saúde define-a como "o uso de força física ou poder, em ameaça ou na prática, contra si próprio, outra pessoa ou contra um grupo ou comunidade que resulte ou possa resultar em sofrimento, morte, dano psicológico, desenvolvimento prejudicado ou privação" (OMS, 2007, p. 1165).

Esta definição traz um ponto-chave, que é a intencionalidade do ato, independente do resultado produzido. Priorizou-se o conceito da OMS tendo em vista que a mesma amplia a definição de violência, não a entendendo apenas como um sofrimento ou morte, por exemplo, indo além da violência contra indivíduos, abrangendo famílias e grupos.

De acordo com o artigo $7^{\circ}$ da Lei $n^{\circ}$ $11.340 / 2006$, são formas de violência doméstica e familiar contra a mulher, entre outras: I - a violência física; II - a violência psicológica; III - a violência sexual; IV - a violência patrimonial; $\mathrm{V}$ - a violência moral, entendida como qualquer conduta que configure calúnia, difamação ou injúria.

Evidencia-se que a violência aparece entre diversos contextos, sejam eles sociais, culturais ou políticos. Percebe-se que ela é um problema de saúde pública, não restrito apenas ao campo individual, mas como um fenômeno socialmente produzido, conforme esclarecem Guareschi e outros (2006).

Toneli, Beiras, Clímaco, e Lago (2009) ressaltam que a violência, além de ser um problema de saúde pública, é um problema de saúde mental, haja vista que as pessoas envolvidas nesse processo podem apresentar alguns riscos como "desordens alimentares, alcoolismo, uso de drogas, estresse pós-traumático, depressão, ansiedade, fobias/pânicos, baixa autoestima e etc.", segundo os autores verificaram no Estudo da Organização Pan-Americana da Saúde de 2003.

Os estudos sobre violência categorizam-na de acordo com a natureza do ato: violência física, psicológica, negligência, violência sexual e exploração sexual. De acordo com dados do Mapa da Violência (Waiselfisz, 2012), a violência física se refere ao uso da força com o objetivo de ferir, deixando ou não marcas evidentes. Ela ocorre quando uma pessoa, que está em posição de poder em relação à outra, causa ou tenta causar dano não acidental, por meio do uso da força física ou de algum tipo de arma que possa provocar ou não lesões externas, internas ou ambas. Já a violência psicológica é caracterizada pela rejeição, depreciação, discriminação, humilhação e desrespeito. A negligência é ato de omissão do responsável pela criança/idoso/outra (pessoa dependente de outrem) em proporcionar as necessidades básicas - necessárias para a sua sobrevivência, para o seu desenvolvimento.

A violência intrafamiliar diz respeito, por conseguinte, a "toda ação ou omissão que prejudique o bem-estar, a integridade física, psicológica ou a liberdade e o direito ao pleno desenvolvimento de outro membro da família, incluindo pessoas que passam a assumir função parental, ainda que sem laços de consanguinidade, e em relação de poder à outra" (Ministério da Saúde, 2001).

Lima e Büchele (2011) afirmam que os Programas de Políticas Públicas acerca da atenção, prevenção e enfrentamento à violência doméstica e familiar destinam-se em maior número às mulheres. Os homens autores de violência muitas vezes acabam sendo excluídos desse contexto. Segundo o autores, duas exceções foram localizadas: a Campanha do Laço Branco, que busca sensibilizar e envolver os 
homens pelo fim da violência contra as mulheres, e o projeto Siga Bem Mulher, cuja temática relaciona-se aos caminhoneiros.

De acordo com a Lei 11.340/06, conhecida como Lei Maria da Penha, recomenda-se "a criação de centros de educação e de reabilitação para os agressores". Embora a Lei seja um marco no que tange aos serviços destinados a homens autores de violência contra mulher, tendo em vista que lhes prevê atendimento, bem como a obrigatoriedade de homens autores de violência participarem de programas de recuperação e reeducação, nota-se que esses serviços não são realizados em todos os territórios nacionais, como é o caso de Florianópolis/SC.

Beiras problematiza que são muitas as dificuldades para a criação de serviços como estes, tais como:

Local que atenda a esses homens, políticas públicas ainda ineficientes, mudanças de gestão por questões políticas e fim de mandatos que interrompem serviços iniciados, desconhecimento sobre serviços similares para troca de experiências, necessidade de capacitação continuada dificultada pela falta de recursos e dificuldades de gestão, e dificuldades ainda presentes de desenvolvimento e captação de recursos. (Beiras, 2014, p. 5)

O trabalho com homens autores de violência ainda é um tabu para alguns profissionais e até mesmo para os próprios homens, que num primeiro momento não compreendem o motivo da obrigatoriedade de frequentar os grupos.

Para trabalhar com este público, o profissional precisa, antes de tudo, "despir-se" de seus preconceitos, tarefa essa que muitas vezes é difícil, tendo em vista a história singular de cada pessoa. Nesse viés, trabalhar com homens autores de violência é atuar na contramão da patologização e perceber esse homem com suas potencialidades, ou seja, alguém com predicados, e não apenas o rótulo de "agressor".

Nos casos de violência conjugal, muitos homens acabam excluídos do processo e tornam-se figuras que devem ser punidas a todo custo. Não havendo na sociedade o entendimento sobre a importância dos serviços que atendam homens autores de violência contra a mulher, os comportamentos agressivos se perpetuam sem uma intervenção adequada.

Compartilho a ideia de Medrado e Lyra (2003), no que se refere à compreensão da violência de homens contra as mulheres a partir da perspectiva de gênero, a suas experiências de vida e suas formas de compreender o fenômeno da violência. Conforme os autores, faz-se necessário conhecer os significados que os homens dão ao ato violento.

Neste sentido, é preciso ampliar o olhar frente à violência contra a mulher, já que ela envolve estruturas de poder e aspectos culturais enraizados em nossa sociedade. Essas estruturas e padrões culturais vão construindo nossas formas de pensar e agir frente a esse fenômeno, para ir na contramão de conceitos reducionistas homem $\mathrm{x}$ mulher (biológico), compreendendo, assim, como homens percebem a sua masculinidade, por exemplo.

É de suma importância pensar em políticas públicas que atuem para além de punir o dito "agressor". É imprescindível pensar em estratégias que promovam uma transformação do ato violento, bem como a responsabilização do autor de violência. Neste viés, universidades também podem ter papel fundamental no âmbito das 
políticas públicas. Nota-se que o desafio também consiste em reconhecer os grupos reflexivos como uma forma de pensar políticas públicas. Cabe destacar que é fundamental pensar em estruturas e locais adequados, assim como profissionais qualificados e metodologia específica em casos de violência contra mulheres.

\section{PERSPECTIVAS ABORDADAS E SUAS REFLEXÕES}

A Teoria da Complexidade ou pensamento complexo nos permite ampliar nosso pensamento sobre os episódios cotidianos e sobre as pessoas, rompendo com pensamentos simplificadores e visões fragmentadas de mundo. Essa teoria não se reduz a regras simplistas; ela reconhece o indivíduo e o concreto. Segundo Morin e Le Moigne (2000, p. 207), o pensamento complexo é capaz de contextualizar, de globalizar, mas, ao mesmo tempo, de reconhecer o singular, o individual, o concreto.

Propõem pensar complexamente, ou seja, além do pensamento reducionista, fragmentado e simplista. Esclarece Morin (1998) que o todo é complexo, como as partes. Desta maneira, a complexidade está presente em tudo em nossa volta. Tal percepção faz com que as influências internas e externas que o indivíduo recebe no seu meio sociocultural sejam determinantes do pensamento complexo.

Corroborando as ideias de Morin (1998), é possível afirmar que o pensamento complexo nos permite ampliar o conhecimento frente a um determinado fenômeno. Quando percebemos um acontecimento de maneira fragmentada e reducionista, acabamos tendo uma visão simplista, não o reconhecendo na sua complexidade.
Nos casos de violência é comum, em nossa sociedade, fragmentar as partes envolvidas: "vítimas" x "agressor". Esse pensamento linear acaba prejudicando o entendimento da violência e estigmatizando as partes envolvidas. Nesse sentido, o pensamento complexo também nos permite entender o contexto no qual a violência está inserida, bem como os aspectos relacionais envolvidos nesse processo.

Desse modo, o pensamento complexo nos ajuda a compreender que a ênfase desses processos está nas relações e não nos próprios indivíduos, que passam a fazer parte dessa trama de relações. O mundo é entendido, desse modo, como uma rede de relações que estão inter-relacionadas (Vasconcellos, 2010).

Bronfenbrenner (1979/1996) explica que os sistemas precisam ser analisados em sua totalidade, sendo entendidos tanto no nível macro (aspectos sociais), intermediários (cultura), assim como no nível proximal (escola e família). Scantamburlo, Moré e Crepaldi (2012) esclarecem que ao trabalhar apenas com as partes, o profissional pode correr o risco de cair em possíveis armadilhas, que são as escutas fragmentadas de um determinado fenômeno. Ou seja, nos casos de violência, por exemplo, a "vítima” é escutada e seu discurso tomado como real; já no caso do "agressor" essa escuta muitas vezes vem permeada por preconceito e julgamento.

Outra prática utilizada foi a terapia narrativa de re-autoria, de $\mathrm{Mi}$ chael White, desenvolvida na década de 1980. Este autor defende a ideia de que as experiências são organizadas de modo narrativo e que a construção de sentido sobre o mundo e sobre nós se processa a partir da construção e da desconstrução de histórias (Santos, Lopes, e Neufeld 2013).

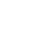


O modelo narrativo de re-autoria de White e Epston (1990) parte da ideia de que as histórias são centrais para a compreensão de um trabalho narrativo. A narrativa do paciente pode estar relacionada ao modo de entender o mundo, sua história de vida, sendo que as experiências diárias do paciente nos orientam a atribuir significados à sua narrativa. As histórias que os pacientes trazem ao longo dos atendimentos servem como guias ao longo do processo terapêutico. Sendo assim, este modelo caminha ao lado do construcionismo social, referindo-se à construção social da realidade por meio da linguagem.

Autores como Beiras (2009) nos ajudam a pensar que as narrativas pessoais referem-se às histórias que contamos e recontamos de nós mesmos, histórias repletas de crenças, valores e sentimentos que nos guiam na nossa maneira de agir e pensar. Assim, ao trabalhar com as narrativas pessoais, é possível trazer novos significados às experiências vividas, como, por exemplo, uma história de violência.

Optou-se por utilizar estas perspectivas por compreender que se entrelaçam e se complementam. Neste contexto, ao trabalhar sistemicamente e atento à complexidade, o terapeuta tem uma visão do todo e das suas múltiplas relações, compreendendo não apenas o ato violento em si, mas toda sua trama relacional. Ao contar sua história, portanto, o paciente revive seu passado e presente, contando, recontando-a e tendo a possibilidade de reescrever novas histórias. Ou seja, a abordagem narrativa permite ao indivíduo, ao contar sua trajetória para um ouvido atento à edição, às exceções, dar sentido sobre o mundo através da construção e desconstrução de suas histórias. Por fim, entende-se que a mudança individual permite a trans- formação em todo o sistema familiar, assim como a alteração deste sistema permitirá a mudança no indivíduo.

\section{COMPREENDENDO E ANALISANDO 0 CASO CLÍNICO}

Antes de fazer terapia individual na clínica-escola, Fábio e Bruna faziam terapia de casal na mesma instituição em que funciona a clínica-escola. Desde o início das sessões, Fábio explicava que seu relacionamento com Bruna era de "idas e vindas". Fábio teve no total seis relacionamentos afetivos, sendo que Bruna foi seu quarto relacionamento. Cabe mencionar que Fábio e Bruna romperam aproximadamente dezoito vezes no período da terapia de casal e individual.

O paciente explica que, antes de conhecer Bruna, era casado há mais de dez anos e o que acarretou a separação foi a relação extraconjugal com Bruna. $\mathrm{Na}$ época dos atendimentos, Fábio tinha trinta e oito anos e Bruna trinta e quatro anos. As sessões eram semanais e o paciente sempre se mostrou assíduo e preocupado, caso precisasse faltar ou se atrasar. O período dos atendimentos foi de 2015 a 2017 e, por motivos profissionais, Fábio decidiu encerrar a terapia, que durou um ano e meio.

A decisão de fazer terapia individual surgiu com a ideia do casal de trabalhar questões individuais, para que, se fosse o caso, fosse retomada a terapia de casal e a união. No entanto, com a terapia individual, os dois foram percebendo que o relacionamento não estava trazendo benefícios para nenhum deles, mas sim brigas, desconfiança, agressão e desrespeito de ambas as partes. O relacionamento durou sete anos, entre idas e vindas, sendo dez meses o maior período ininterrupto. 
Féres-Carneiro (1998) traz a noção de modelo único de casal, que se refere às individualidades do casal que formam uma conjugalidade. De acordo com a autora, cada um dos cônjuges traz consigo sua história pessoal, sonhos, medos, expectativas... Estes componentes se somam para estabelecer uma história a dois. Neste viés, Apreende-se então que, caso não exista um equilíbrio entre esses componentes, a manutenção do casamento e seu equilíbrio se tornam um desafio.

Fábio foi denunciado por Bruna pela primeira vez em 2012, após um conflito relacional que resultou em agressões; na época, ele estava com Bruna. O conflito foi motivado por uma discussão, que, segundo ele, começou por conta de divergências na hora de fazer compras no supermercado. Fábio relatou que Bruna o provocou falando que, com "o outro", não tinha problemas, fato este que o incomodou e o deixou 'nervoso'. Quando chegaram em casa, a briga se estendeu e Fábio conta que agrediu Bruna fisicamente. O mesmo explicou que a vizinha escutou os gritos e tentou "apartar" a briga, mas também acabou se machucando.

Ravazzola (1997) explica que a violência familiar é um fenômeno que se repete e que acontece num sistema abusivo em que existem pessoas que cometem o abuso, a receptora do ato abusivo e as testemunhas (vizinhos, filhos, primos, amigos e outros membros). No caso de Fábio, ora ele era considerado a pessoa que cometeu o ato violento, ora era ele quem sofria o ato violento, tendo em vista que a ex-esposa já o agredira verbalmente e fisicamente. A vizinha e seus filhos muitas vezes eram as testemunhas dos episódios de agressão, tanto por parte de Fábio, como de Bruna.

Em uma determinada sessão, pergunto a Fábio como ele se sentia nos momentos de raiva e quais os sentimentos ele tem em momentos de conflito como este que culminou em agressão. Faço as seguintes questões: $\mathrm{O}$ que seu corpo sente quando você está em um momento de raiva? Cite um momento onde essa raiva poderia ter assumido o seu controle, mas você não permitiu.

$\mathrm{O}$ paciente disse que nesses momentos sente uma "tremedeira, osso da canela esfarelando, coração dispara e sente muita raiva" (sic). O paciente lembrou que essas reações ele sentia no início das sessões. Após alguns meses de terapia, foi possível verificar mudanças no controle da ira e nos significados dados à raiva.

Fábio comentou que não permitia que a raiva assumisse o controle em alguns momentos em que Bruna o provocava com insultos. Fábio ainda explica como eram as provocações que sofria: "Bruna falava que os outros homens que ela conheceu eram melhores que eu". Em alguns momentos, Fábio conseguiu sair de cena, ou seja, tomava um copo de água, respirava fundo, contava até dez, ou até mesmo saía de casa e esperava "a poeira baixar", esperava os ânimos acalmarem-se, para que, assim, pudesse ter um diálogo sem violência e agressões.

Perguntei, como terapeuta, se essa forma de lidar com a raiva foi melhor ou pior para ele. Fábio esclareceu que essa forma o ajudou não apenas na sua vida pessoal, mas também na vida profissional. Ele exemplificou um episódio no trânsito, onde "cortaram a frente" dele. Fábio explicou que se fosse em outros tempos, ele iria "xingar" o "cara" e "cortar a frente". Fábio disse que respirou fundo, deixou "o cara seguir seu caminho" e não tomou aquela ação como pessoal.

Andersen (1999) nos ajuda a pensar em outras formas construtivas de 
trabalhar as significações. Outras perguntas possíveis seriam: "Se a raiva pudesse te dizer algo, o que ela diria? Se ela te reclamasse algo, seria o quê? Essas perguntas também poderiam suscitar reflexões e significações da raiva a ele, favorecendo o exercício do tempo fora, ou o "sair de cena".

Nas histórias de intergeracionalidade do paciente foi possível verificar padrões repetitivos de infidelidade conjugal. A teoria sistêmica nos consente compreender o sujeito de forma mais abrangente, entendendo a família, meio social, econômico e cultural. Ao trabalhar com o indivíduo, também devemos analisar o sistema familiar do mesmo. Um dos recursos possíveis para se analisar o sistema familiar segundo Carter e McGoldrick (1995) é o genograma familiar.

De acordo com Lisboa, Feres-Carneiro, e Jablonski (2007), o conceito de transmissão intergeracional "compreende a transmissão de uma geração à seguinte de legados, rituais e tradições, a qual pode ser consciente ou inconsciente". Destarte, a transmissão intergeracional permite continuar repassando crenças, ideologias e ensinamentos de geração em geração. A transmissão intergeracional de violência na vida de Fábio foi muito presente - foram ensinamentos repassados, seja na forma de educar de forma violenta, ou de expressar seus sentimentos de forma violenta.

Neste sentido, para Scantamburlo et al. (2012), os modelos de comportamento que são pautados na violência podem ser transmitidos entre gerações, sendo muitas vezes naturalizados. Muitos dos comportamentos perpetuados são, por consequência, repetições de atitudes, crenças e ideologia que são transmitidas ao longo de gerações.

No que concerne às histórias de intergeracionalidade de Fábio, em al- guns momentos da terapia foi possível identificar que esses processos eram conscientes, na medida em que alguns dos conteúdos herdados foram percebidos pelo paciente, como a conduta agressiva para educar seus filhos, que posteriormente passou para uma conduta de diálogo. No que tange à educação dos filhos, cabe mencionar que Fábio tem quatro filhos, sendo que dois são do relacionamento com Bruna.

Como afirmam Scantamburlo et al. (2012), é necessário que não se entre na armadilha de pensar que todos que sofreram algum tipo de violência, por exemplo, irão perpetrá-la. Nesse ínterim, o pensamento sistêmico permite vislumbrar outras possibilidades de mudanças, potencialidades e recursos que não sejam apenas o comportamento violento.

Scantamburlo et al. (2012), ao se pensar no processo de violência, afirmam que devemos entendê-lo como uma trama relacional, na qual todas as partes envolvidas se afetam recursivamente. Essa perspectiva nos permite compreender a violência como sendo interacional, e não como constitutiva de um único indivíduo.

Os aspectos relacionados à transgeracionalidade, de certa forma, acabaram por influenciar os comportamentos e atitudes do paciente. O termo transgeracionalidade, definido por Falcke e Wagner (2005), remete-se ao fenômeno de perpetuação da família através da transmissão de legados de geração em geração nas mais diferentes culturas. Neste sentido, o indivíduo é compreendido tanto na sua esfera familiar, com suas histórias e legados, como nas esferas social, econômica, política e cultural.

O modelo transmitido pela família de Fábio indica modelos patriarcais e rígidos sobre a concepção de mulher e criação dos filhos, por exemplo. 
Também foi possível perceber certa similaridade ou complementaridade na motivação pela escolha de Bruna como parceira, que, segundo Fábio, tem muitas características de sua mãe.

Sobre a figura materna, Fábio relata que sua mãe era ríspida, grosseira e teimosa. Conta que seu pai (de criação) tentava conversar e nunca bateu nos filhos ou na esposa. Acrescenta que a relação entre seus pais não tinha afeto e demonstrações de amor. Explica que, com a mãe, tudo era na "base da cinta", não havia diálogo, ao contrário de seu pai, que resolvia as coisas na base do diálogo, embora descontasse sua raiva nos objetos da casa.

Durante os atendimentos, foi possível observar uma relação conturbada entre o ex-casal, já que ambos entravam em conflito e faziam "jogos" de ciúmes e ameaças. Nota-se um ciclo vicioso entre eles, onde ambos se agridem tanto fisicamente como psicologicamente.

Corroborando as ideias de Bowen (1991), para compreender a família e seu funcionamento, é de suma importância desvendar o que aconteceu nas gerações anteriores. Trata-se de uma oportunidade de ampliar o olhar e trabalhar questões como segredos, mitos e repetições familiares. No caso de Fábio, o uso de genograma foi fundamental, pois foi possível revelar segredos, mitos, histórias de repetições, como traição e violência.

\section{ESTRATÉGIAS SISTÊMICAS}

Ao longo do trabalho clínico, foi sugerido que Fábio fizesse uma retrospectiva e pensasse no que faria de diferente em relação ao episódio da agressão. Em um momento do processo terapêutico, ele disse: "Não penso em relação a não bater, mas já teria termi- nado com ela na primeira vez que ela me traiu. Esse que foi o problema. Não tinha mais confiança nela". Foi perguntado durante a sessão: $\mathrm{O}$ que a Bruna significava em sua vida? Ele respondeu: "A Bruna era como uma droga, eu sempre tinha que arrumar um jeito dela estar comigo, transar comigo. É como um dependente, se treme todo, arruma um jeito. $\mathrm{O}$ que me atraiu nela foi o sexo. Hoje percebo que era apenas o sexo. Foi por isso que voltamos dezoito vezes".

Nota-se, nesse trecho, a ressignificação de Fábio em relação à Bruna em sua vida, assim como o fato de percebê-la, em retrospectiva, como 'objeto sexual', afastando-se do afeto. Observa-se no discurso de Fábio ligação com os aspectos sociais patriarcais e machistas implícitos, repercutidos e que são, quase sempre, contidos nos casos de violência contra a mulher.

Nas primeiras sessões com o paciente, foi solicitado que o mesmo fizesse um checklist de como seria uma "mulher ideal", as qualidades que ele percebia nela, o que mudou e o que gostaria de mudar. Depois de um ano de terapia, foi retomado esse checklist a fim de avaliar possíveis mudanças ou se ele gostaria de acrescentar ou mudar algo. Esse exercício teve o objetivo de visualizar, no período de um ano, mudanças, crescimento e outras formas de se perceber.

Após doze meses de terapia na clínica-escola, retomou-se o checklist e, em relação à "mulher ideal", o paciente comentou que espera que uma mulher seja: calma; independente financeiramente, para se ter um equilíbrio; dependente emocionalmente (o paciente trocou por 'submissa'), ou seja, "que não bata de frente comigo"; e que tenha os mesmos gostos que o dele: "filme, cinema, que seja bonita, charmosa e se vista bem" (sic). 
A partir do discurso de Fábio foram analisadas questões voltadas aos discursos, modelos socialmente valorizados de homem e mulher, ou seja, estereótipos. Foi possível também observar questões relacionadas à sociedade machista, que tem o ideal de mulher que seja submissa ao homem. Segundo o pensamento sistêmico, essas questões fazem referência a fatores socioculturais que influenciam o comportamento e acabam sendo pautados por padrões esperados de comportamento.

Sobre suas "qualidades", o mesmo respondeu que se considera uma pessoa atenciosa, amorosa, resiliente, trabalhadora, honesta, inteligente, dedicada, persistente e bondosa. Ao ser perguntado quais as mudanças pelas quais passou no processo da terapia, Fábio respondeu: "não sou mais agressivo, sou mais calmo no trânsito, não falo mais o nome da ex com tanta frequência, espero a confirmação das coisas para cobrar".

Após algumas perguntas reflexivas, Fábio pôde perceber que estava "submerso" ao relacionamento com Bruna, o que não o permitia estabelecer outros laços sociais, bem como se concentrar no trabalho, já que seu pensamento estava apenas em Bruna: se ela iria traí-lo ou não. As perguntas reflexivas giram no sentido de resgatar o Fábio que estava escondido atrás de Bruna, já que ele estava inseguro diante do seu papel social abalado, ou seja, o mesmo utilizava da violência como reação e restabelecimento de poder.

Ao utilizar a proposta reflexiva de Tom Andersen, que nos ajuda a repensar, (re) construir e transformar determinada realidade, abriu-se um espaço de diálogo e troca, favorecendo a construção e reconstrução de significados sobre o que Fábio pensava e acreditava sobre violência, o lugar social atribuí- do a homens e mulheres e sobre os recursos que ele poderia ter frente aos comportamentos violentos.

Ao longo do processo terapêutico foi possível perceber que Fábio estava mais calmo, pensava antes de agir e tomar decisões na sua vida pessoal, afetiva e amorosa. Mudança esta que Fábio percebeu durante as sessões e salientou como importante para ele e para as pessoas com que convivia.

Após ser perguntado sobre as coisas de que ele gostava de fazer, dos seus desejos profissionais e de sua perspectiva para o futuro, Fábio conseguiu traçar seus objetivos profissionais e como ele poderia fazer para alcançá-los. Começou a trabalhar como motorista particular, trocou de carro e almejava começar um curso para piloto.

O que gostaria de mudar: "ter mais vida social; não ser tão ciumento e desconfiado; ser mais calmo no geral; e deixar de centralizar tudo em sexo" (sic). Após um ano, o paciente percebe que mudara todos esses itens. Relatou que uma vez por semana vai ao cinema, seja sozinho ou com sua filha (casamento com Roberta). Diz que não é mais desconfiado e ciumento, já que sabe ouvir mais e prioriza o diálogo.

Fábio relata como ele percebe o ciúme: "Ciúme é como câncer, tá ali, desperta ou não. Se for leviana, aprontar, mentir ou omitir, claro que vai ser desconfiado. Tem que cair fora logo de cara. Até na educação dos meus filhos estou diferente, hoje em dia eu baixo na mesma altura dos meus filhos e converso" (sic).

Em relação ao processo de terapia, Fábio esclareceu que "sou nervoso, mas com a terapia estou colhendo bons frutos. Hoje em dia eu consigo respirar fundo, consigo 'sair de cena'. Estou mais calmo em relação a tudo, mais calmo até no trânsito. Hoje respiro fundo e deixo passar". 
Ao investigar como o paciente percebia a técnica de 'sair de cena', o mesmo explicou: "sair de cena dá menos rolo, porque você respira fundo, pensa: será que tenho que agir assim? E no outro dia pensa melhor. Percebi que assim é melhor e não é tão difícil como eu pensava. Tem me ajudado muito e se o outro não consegue 'sair de cena', o outro precisa, senão tem briga e agressão".

Perguntei em uma das sessões: Como você se sente quando usa essa técnica e como você se percebe após ter 'saído de cena'? Ele respondeu: “Me tranquiliza, dá tempo de pensar e ter outra atitude. Eu comecei a raciocinar e não agir mais por impulso. Eu perdia a razão e passava a ser malvisto, talvez se eu tivesse virado o jogo antes, se tivesse saído de cena. Maria da Penha pesa mais que tudo. Coloca $10 \mathrm{~kg}$ de pedra e a Lei vale mais."

Embora essa técnica seja de base cognitiva, optou-se por um olhar sistêmico, a fim de se compreender aspectos macrossistêmicos que levaram o paciente a tomar determinada ação, explorando histórias de violência presentes em sua história de vida - construção social. Neste contexto, a técnica se mostrou útil, tendo em vista que Fábio conseguiu cessar a violência.

No que concerne à Lei Maria da Penha, o paciente expressa que a Lei é muito seletiva: "se fosse num país europeu, por exemplo, ela iria funcionar. Aqui no Brasil não se tem uma investigação, não querem saber o motivo de quem bateu, o que levou ao episódio em si. Apenas chamam o cara de vagabundo e prendem". Fábio ainda afirma que a lei não é igual para todos, não se tem um interesse por parte das autoridades em investigar o caso: "parece que é meio que um sorteio: esse vai pagar em cesta básica, esse vai cumprir três anos em regime fechado, esse vai prestar serviço comunitário".
Essa questão levantada por Fábio explicita a carência de um atendimento qualificado e eficiente, quando muitas vezes o homem autor de violência é apenas julgado e punido, sem ao menos vislumbrar uma possibilidade de escuta e ressignificação e superação do ato violento, somado às dificuldades já apontadas anteriormente por Beiras (2014) de implementação dos programas de apoio. Araújo (2008) dialoga com Saffioti (2004) ao problematizar a ideia de violência olhando para os dois "espectros", ou seja, olhar a violência não apenas em relação à vítima, mas também voltar o olhar para o agressor. Desse modo, é possível buscar uma real transformação da relação.

Neste caso, e em outros presentes na clínica-escola, os conflitos familiares não são apenas de violência física, mas muitos casos ficam camuflados, como é o exemplo de violência psicológica e sexual. Acerca do problema de Fábio, observa-se a violência física e psicológica de mãos dadas, onde ambos se atingiam e chegavam às vias de fato agressão.

Hoje o paciente percebe que não tinha esse "autocontrole" que tem atualmente, mas ressalta que não sabe se ainda o tem em relação à Bruna, já que nem tem o interesse em "testar". Os modelos educacionais e as histórias transgeracionais de Fábio permitiram adentrar profundamente a sua vida. Foi perguntado, ao longo das sessões, como eram os padrões de relacionamentos aprendidos por cada membro da família, quais lembranças tinha da educação dos pais, quais lembranças ele tinha dos momentos de lazer e carinhos com os pais e quais cicatrizes ele tinha da infância.

No que tange aos modelos educacionais do paciente, verificou-se um modelo patriarcal e machista que inclui castigos físicos. Como Fábio sem- 
pre teve o padrão educacional de bater, ele acreditava que dar limite era bater nos filhos. Após o processo terapêutico, Fábio pôde perceber outras formas de educar que vão além da agressão.

"Na época em que estava com Bruna eu metia os 'pés pelas mãos'. Eu a cobrava muito e era agressivo. Hoje percebo que cada um tem sua particularidade. Hoje só penso em estar com alguém que me traz segurança, porque antes eu estava intoxicado com a Bruna, talvez a distância fez eu me desintoxicar dela."

Ao ser perguntado como ele percebia a terapia, o mesmo respondeu que "A terapia me ajudou a ter discernimento em relação às coisas. Hoje eu me olho mais, me preocupo com meu profissional e percebo que estou progredindo. Estou me aperfeiçoando e buscando crescer profissionalmente. Antes ficava preso apenas nos relacionamentos e não me olhava" (sic).

$\mathrm{O}$ processo terapêutico acaba se tornando um espaço de diálogo, onde existem trocas significativas para intervenção terapêutica, bem como o respeito e a flexibilidade. Neste sentido, além de trabalhar questões relativas ao que culminou em sua condenação, foram abordadas questões compatíveis ao trabalho, modo de vida, questões ligadas à paternidade e planos futuros, por entender que Fábio é muito mais do que um homem autor de violência.

Foram criadas perguntas no sentido de abrir espaço e descobrir resultados positivos. Esses exercícios conversacionais admitem focar nos pontos positivos e externalizar o problema. De acordo com White e Epston (1990), a externalização permite que o paciente dê outro significado a alguma história trazida, como, por exemplo: "como você agiu quando percebeu que sua raiva poderia tomar controle sobre você?”. “- Eu respirei fundo e resolvi sair do conflito. Depois a gente se acalma e começa a raciocinar melhor." Esse exercício fez com que Fábio pudesse dar um nome à sua "raiva" e enxergá-la como não constituinte dele. Ademais, ele pôde refletir sobre sua raiva e trilhar outros caminhos - diferentes da agressão física.

Vale aqui lembrar um trecho de uma música de Vanessa da Mata, que traduz o processo terapêutico: "Reguei com tanta paciência / Podei as dores, as mágoas, doenças / Que nem as folhas secas vão embora / Eu trabalhei”.

Ao longo do processo terapêutico foram perceptíveis as mudanças de Fábio e seu anseio por fazer diferente, não mais por Bruna, mas por ele. A Lei 11340/06 é injusta na opinião de Fábio, no sentindo de não permitir ao homem expor seus sentimentos, anseios e razões. Ele entende que Bruna teve comportamentos provocativos que culminaram na agressão, mas pensa que poderia ter feito diferente, ou seja, "não cair nas provocações".

Hoje o paciente busca um relacionamento em que possa ter um diálogo, onde ambos possam expor seus sentimentos e que sejam respeitados, mesmo com opiniões opostas. Isso foi possível tendo em vista que Fábio pôde ressignificar aspectos de sua vida pessoal, profissional e amorosa.

Fábio mostrou que até a flor mais seca pode ser regada, pode crescer e florescer. Sim, foi um processo que exigiu paciência, tanto da terapeuta como do paciente, mas os dois puderam florescer.

Quando é dito que Fábio floresceu, significa dizer que ele pôde trabalhar em terapia sua autoestima, passou a se valorizar mais, tanto como pessoa, como profissional. Buscou outros projetos profissionais, aprimorou-se profissionalmente e está trilhando seus sonhos e objetivos. 
No atendimento com homem autor de violência, foi possível perceber que o autor da violência deve ser responsabilizado. No estudo de caso, Fábio se colocou como o autor da violência, mas também se colocou como agredido, seja pela ex-companheira, seja pela Lei, pois, segundo ele, foi impossibilitado de expor seus argumentos perante a justiça ou pela sociedade que acaba por segregar e não reconhecer que $\mathrm{o}$ autor de violência também pode ressignificar o seu ato e, possivelmente, não cometê-lo mais.

Assim, é preciso pensar em políticas públicas mais eficazes para o atendimento aos homens autores de violência. Pensar em políticas públicas não requer criminalizar e prender, mas criar estratégias e recursos para que esses homens possam transcender ao ato violento e ressignificar suas atitudes e crenças. Por fim, se faz terapêutica a possibilidade de contar e recontar histórias de vida, sobretudo se essas histórias puderem ser ressignificadas e reconstruídas.

\section{PROCESSO TERAPÊUTICO: CAMINHOS POSSÍVEIS}

A visão sistêmica permitiu identificar discursos e questões intergeracionais, assim como repetições que contribuíam para a continuidade do problema, e trabalhar no sentido de mudanças e transformações. Possibilitou um olhar que fugisse das patologizações, rótulos, fazendo assim com que o indivíduo pudesse ser percebido segundo suas potencialidades e resiliências. Ao longo da terapia, percebeu-se a implicação e o desejo de mudança por parte de Fábio, que, muitas vezes, mostrou-se insatisfeito por não ser ouvido nas instâncias judiciais.

A perspectiva de gênero também orientou o nosso trajeto terapêutico.
De acordo com Beiras e Bronz (2016), no nosso meio social ainda perdura a ideia sexista, o que corrobora o comportamento violento de muitos homens, por exemplo.

Ao ser mulher e atender um homem autor de violência, foi possível trazer questões de gênero e me colocar enquanto mulher. Fábio ressaltou inclusive o fato de ser atendido por uma mulher, já que, segundo ele, "se sentia mais à vontade".

Foram feitas perguntas abertas e reflexivas, visando ao entendimento do processo de violência: como se dava, como ela ocorria, quais eram os envolvidos e o que a suscitava. Entende-se que a terapia tem que ir além de focalizar os "problemas"; ela também precisa identificar as potencialidades, ou seja, o que há de positivo na pessoa. Neste viés, Fábio conseguiu identificar competências que nem ele reconhecia em si.

Foi possível perguntar: como eram os momentos de lazer com os filhos? Como ele se sentia nos momentos em que estava com os filhos? Fábio sempre se mostrou um pai participativo na educação dos seus dois filhos, os que teve com Bruna. Ao longo das sessões, quando era perguntado sobre os filhos que estão em outro Estado, seus olhos se enchiam de lágrimas e ele demonstrava saudade, carinho, afeto e um desejo de estar novamente com eles.

Pôde-se trabalhar com Fábio quais são os recursos existentes no momento em que um conflito se instaura. Recursos que vão além de uma discussão ou de uma briga, por exemplo. Fábio conseguiu vivenciar, experimentar e levar com ele a técnica de "sair de cena"; método que ele diz ter sido fundamental no seu processo. Fábio conseguiu também perceber que o diálogo é primordial, que ouvir o outro também se faz necessário, que as pessoas podem ter

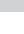


opiniões diversas, e não é porque o outro não concorda com nossa forma de pensar que ele está nos desrespeitando.

Ao sair da ideia de um "suposto saber do terapeuta" e coconstruir a sessão com o paciente, foi possível adentrar o mundo de Fábio e validar e re-conhecer suas experiências e vivências. $\mathrm{O}$ vínculo e a confiança foram fundamentais neste processo porque facilitaram a construção no trabalho com esse homem autor de violência.

Ao longo do processo terapêutico, Fábio foi contando o quão sofrido é carregar o estigma de "agressor". O estigma, segundo Goffman (2004), refere-se aos estereótipos sociais, estando ligado à construção social de uma determinada cultura. Ou seja, a sociedade vê o homem autor de violência como agressor, violento, criminoso e muitas vezes classifica essas pessoas como "doentes". Esses atributos acabam por moldar e criar rótulos a esse homem; trata-se, como salienta Goffman, "[d]a situação do indivíduo que está inabilitado para aceitação social plena" (Goffman, 2004, p. 4).

Compreendeu-se um pouco, a partir do discurso de Fábio, como a sociedade alimenta cada vez mais o preconceito frente em relação àquele que é visto como "agressor", como a justiça também corrobora esse pensamento ao não oferecer um espaço de escuta, diálogo e, principalmente, transformação.

Fábio externou que os impactos da Lei $n^{\circ} 11.340$ foram inúmeros, seja na vida pessoal, profissional e nos seus relacionamentos. Relatou que seu sonho de fazer um curso para piloto teve que ser adiado, tendo em vista que estava com "a Lei nas costas". Neste sentido, sua vida deu uma estagnada, já que ele precisava cumprir o que foi lhe fora estabelecido: serviço comunitário. Porém, ao longo do processo terapêutico,
Fábio conseguiu compreender aspectos positivos no serviço comunitário, já que ele começou a estabelecer contatos profissionais e se sentir importante no trabalho que estava fazendo, onde fez também outras amizades.

Nesse contexto, podemos perceber que foi exequível trabalhar ao longo do processo terapêutico os impactos da Lei. Fábio teve abertura para falar do estigma social que ainda perdura sobre o "agressor". Explicou que algumas pessoas o enxergavam apenas a partir da etiqueta de "agressor" e não como Fábio. Ao final do processo terapêutico Fábio conseguiu se enxergar como Fábio e não apenas como um homem agressivo que cometeu determinado crime, conseguindo ressignificar suas atitudes e crenças e dar um novo sentido para o ato que cometeu.

Os desafios podem ser inúmeros, como em qualquer atendimento. $\mathrm{O}$ profissional tem que estar disposto a entrar na vida do paciente, ouvir, entender, compreender e, acima de tudo, não julgar. Ao ter essa postura, o trabalho terapêutico se torna mais leve, tendo em vista o vínculo terapêutico e o respeito pela pessoa que está confidenciando sua vida, suas angústias, medos e incertezas.

\section{CONSIDERAÇÕES FINAIS}

Reafirmo que, para compreender a violência, é necessário entendê-la como um fenômeno complexo e multifacetado. Podem existir fatores individuais, tais como histórico de violência na família de origem, aspectos relacionais, instabilidade nos relacionamentos, entre outros. Ao falar em violência, devemos nos despir do conceito de vítima $\mathrm{x}$ agressor e assimilar como se dá a dinâmica da violência dentro de cada caso. 
$\mathrm{Na}$ abordagem sistêmica não procuramos culpados, mas sim a apreensão da dinâmica da violência que acontece no meio familiar e qual o papel de cada um nessa família. Assim, compreender a violência é escutar como ela se dá na família, como o indivíduo percebe a violência e seus sentidos para o ato violento.

Ao longo do processo terapêutico trabalhou-se com questões relacionadas ao controle da ira, sendo fundamental falar sobre os mais diversos sentimentos e angústias. Fábio conseguiu se implicar no processo terapêutico e se responsabilizar pelos próprios atos, mas, além da responsabilização, foi possível que ele transcendesse ao seu ato e ressignificasse suas maneiras de vivenciar sua história, de significar a violência como forma de tornar-se homem e sujeito no mundo, e como modo de relacionamento e solução de conflitos.

Acredita-se que o autor da violência deva ser responsabilizado pelos seus atos, mas que o olhar sobre ele seja também de acolhimento da história de cada um, assim como a pessoa que sofreu a violência precisa ser cuidada e protegida. Essas são medidas no âmbito da saúde pública e mental que garantem o cumprimento da Lei 11.340/06 satisfatoriamente. É de suma importância que possamos olhar horizontalmente para os dois sujeitos que estão nesse contexto relacional de violência. Neste sentido, o espaço de reflexão se faz aberto e necessário, já que ele permite que esse homem possa ressignificar suas crenças, sua história e assim se responsabilizar por seus atos e vislumbrar outros modos de constituir relações.

Por fim, a proposta do estudo de caso surgiu por compreender a urgência de promover um espaço diferenciado de escuta e diálogo para que este homem pudesse falar da violência perpetrada, mas, além disso, reescrever sua história, revisitando suas condutas e traçando outros caminhos possíveis. A terapia narrativa também auxiliou no trabalho desenvolvido, possibilitando diálogos interpessoais e intrapessoais, o que abarca sua forma de estar, relacionar-se no mundo.

\section{REFERÊNCIAS}

Acosta, Fr, Andrade, A., \& Bronz, A. (2004). Conversas homem a homem: grupo reflexivo de gênero. Rio de Janeiro: Instituto Noos.

Andersen, T. (1999). Processos Reflexivos. Rio de Janeiro: Instituto Noos.

Araújo, S. (2008). Jovens identificados como autores de abuso sexual: sentidos da violência. Dissertação de Mestrado, Programa de Pós-graduação em Psicologia, Universidade Federal de Santa Catarina, Florianópolis, SC.

Beiras, A. (2009). Grupos de homens autores de violência - possibilidades de intervenções diante das recomendações propostas na lei Maria da Penha. In S. Rovinski \& R. Cruz (Eds.), Psicologia jurídica: perspectivas teóricas e processos de intervenção (pp. 129-144). São Paulo: Vetor.

Beiras, A. (2014). Relatório Mapeamento de Serviços de atenção grupal a homens autores de violência contra mulheres no contexto brasileiro. Recuperado de http:// www.noos.org.br/userfiles/file/ Relat\%C3\%B3rio\%20Mapeamento\%20SHAV site.pdf

Beiras, A. \& Cantera, L. (2012). Narrativas personales, construcción de masculinidades: aportaciones para la atención psicosocial. PSICO, 43(2), 251-259. Recuperado de http://www. revistaseletronicas.pucrs.br/ojs/in- 
dex.php/revistapsico/article/viewFile/10023/80 35

Beiras, A. \& Bronz, A. (2016). Metodologia de grupos reflexivos de gênero. Rio de Janeiro: Instituto Noos. Recuperado de http://noos.org.br/wp-content/uploads/2018/08/Metodologia-Noos PDF-final.pdf

Beiras, A. \& Nascimento, M. (2017). Homens e violência contra mulheres: pesquisas e intervenções no contexto brasileiro. Rio de Janeiro: Instituto NOOS.

Bowen, M. (1991). De la familia al individuo: la diferenciación del sí mismo em el sistema familiar. Buenos Aires: Paidos.

Bronfenbrenner, U. (1996). A ecologia do desenvolvimento humano: Experimentos naturais e planejados. Porto Alegre: Artes Médicas. (Original publicado em 1979)

Carter, B. \& McGoldrick, M. (1995). As mudanças no ciclo de vida familiar (M. A. V. Veronese, Trad.). Porto Alegre: Artes Médicas.

Falcke, D. \& Wagner (2005). A dinâmica familiar da trangeracionalidade; definição de conceitos. In A. Wagner (Org.), Como se perpetua a familia? A transmissão trangeracional do legado familiar (pp. 25-46). Porto Alegre: EDIPUCRS.

Féres-Carneiro, T. (1998). Casamento contemporâneo: o difícil da individualidade com a conjugalidade, Psicologia: Reflexão e Crítica, 11(2), 379-395.

Goffman, E. (1981). Estigma: notas sobre a manipulação da identidade deteriorada. Rio de Janeiro: LTC.

Guareschi, N. M. Fr, Weber, Ans Comunello, L. N., \& Nardini, M. (2006). Discussões sobre violência: trabalhando a produção de sentidos. Psicologia: Reflexão e Crítica, 19(1), 122-130. https://dx.doi.org/10.1590/ S0102-79722006000100017

Leil n. 11.340, de 7 de agosto de 2006. (2006). Cria mecanismos para coi- bir e prevenir a violência doméstica e familiar contra a mulher. Diário Oficial [da] República Federativa do Brasil, Brasília, DF, 8 ago. 2006. Recuperado de <http://www.planalto.gov.br/ccivil $03 /$ ato20042006/2006/lei/l11340.htm $>$.

Lima, D. C. \& Büchele, F. (2011). Revisão crítica sobre o atendimento a homens autores de violência doméstica e familiar contra as mulheres. Physis: Revista de Saúde Coletiva, 21(2), 721-743. https://dx.doi.org/10.1590/ S0103-73312011000200020.

Lisboa, A. V., Féres-Carneiro, Tu, \& Jablonski, B. (2007). Transmissão intergeracional da cultura: um estudo sobre uma família mineira. Psicologia em Estudo, 12(1), 51-59. https://dx.doi.org/10.1590/ $\underline{\text { S1413-73722007000100007 }}$

Medrado, B. \& Lyra, J. (2003). Nos homens, a violência de gênero. In Programa de prevenção, assistência e combate à violência contra a mulher Plano Nacional (p. 68). Brasília, DF: Presidência da República.

Minayo, M. C. L. (Org.). (2007). Pesquisa social: teoria, método e criatividade. Petrópolis, RJ: Vozes.

Ministério da Saúde. (2001). Portaria MS/GM n. ${ }^{\circ} 737$ de 16/05/01. Política nacional de redução da morbimortalidade por acidentes e violências. Diário Oficial da União, Brasília, n. 96, Seção 1E, 18 maio, 2001.

Morin, E. A. (1998). Ciência com Consciência ( $2^{a}$ ed.). Rio de Janeiro: Berhand.

Morin, E. A. \& Le Moigne, J.-L. (2000). A inteligência da complexidade. São Paulo: Peirópolis.

Organização Mundial de Saúde [OMS]. (2002). Relatório Mundial sobre Violência e Saúde. Genebra. Recuperado de www.opas.org.br/wp-content/ uploads/2015/09/relatorio-mundial-violencia-saude.pdf. 
Ravazzola, M. C. (1997). Histórias infames: los maltratos em las relaciones. Buenos Aires: Paidós.

Saffioti, H. (2004). Gênero, patriarcado e violência. São Paulo: Fundação Perseu Abramo.

Santos, W. M., Lopes, R. F. F., \& Neufeld, C. B. (2013). Relaçãoterapêutica eterapia narrativa: entrevista com $\mathrm{Mi}$ guel Gonçalves. Revista Brasileira de Terapias Cognitivas, 9(1), 61-69. https://dx.doi.org/10.5935/1808$\underline{5687.20130009}$

Scantamburl0, N. P., More, C. L. O. 0., \& Crepaldi, M. A. (2012). O processo de transmissão intergeracional e a violência no casal. Nova Perspectiva Sistêmica, 21(44), 35-48, 2012. Recuperado de http://www. revistanps.com.br/index.php/nps/ article/view/250/243

Schmidt, B., Schneider, D. R., \& Crepaldi, M. A. (2011). Abordagem da violência familiar pelos serviços de saúde: Contribuições do pensamento sistêmico. Psico, 42(3), 328-336.

Toneli, M. J. F., Beiras, A.s Climaco, D., \& Lago, M. C. S. (2010). Atendimento a homens autores de violência contra mulheres: Experiências latino-americanas. Florianópolis: UFSC/CFH/ NUPPE.

Vasconcellos, C. S. (2010). Planejamento: projeto de ensino-aprendizagem e projeto político-pedagógico - elementos metodológicos para elaboração e realização (21a ed.) São Paulo: Libertad.

Vidal, A. C. B. (2006). A diferença que fez a diferença: o uso incomum da equipe reflexiva de Tom Andersen. Pensando Família, 10(2), 117-134.

Waiselfísz, J. J. (2012). Mapa da Violência 2012. A Cor dos Homicídios no Brasil. Rio de Janeiro: CEBELA, FLACSO; Brasília, DF: SEPPIR/PR.
White, M. \& Epston, D. (1990). Medios narrativos para fines terapêuticos (O. Castillo, M. Beyebach, \& C. Sánchez, Trads.). Buenos Aires: Paidós.

\section{NÁDIA DE MELO FERREIRA}

Mestra em Saúde Coletiva pela Universidade Federal de Santa Catarina (UFSC), Florianópolis/SC, Brasil.

E-mail: ferreira_nah@hotmail.com 